\title{
Ge-conservación
}

Conservação | Conservation

\section{De Sarajevo a los brioches de María Antonieta. Conversaciones con Arsenio Sánchez Hernampérez}

\author{
Por Rocío Bruquetas y Charo Fernández
}

El Premio Nacional de Restauración y Conservación de Bienes Culturales ha sido otorgado este año de 2013 a Arsenio Sánchez Hernampérez, conservador-restaurador de la Biblioteca Nacional de España, en reconocimiento a una trayectoria que, en palabras del jurado, ha hecho evolucionar la disciplina «hacia un nuevo paradigma científico y ético que sirve de modelo entre profesionales de la conservación y restauración así como de archivos y bibliotecas». Arsenio representa, en efecto, esa evolución profesional experimentada por muchos restauradores desde los últimos 30 años, que han ido completando su formación convencional en las escuelas de restauración con estudios universitarios. Pero en su caso, además, ha incorporado para beneficio de toda nuestra comunidad profesional, un admirable recorrido intelectual y una vocación por trasmitir sus conocimientos que quedan

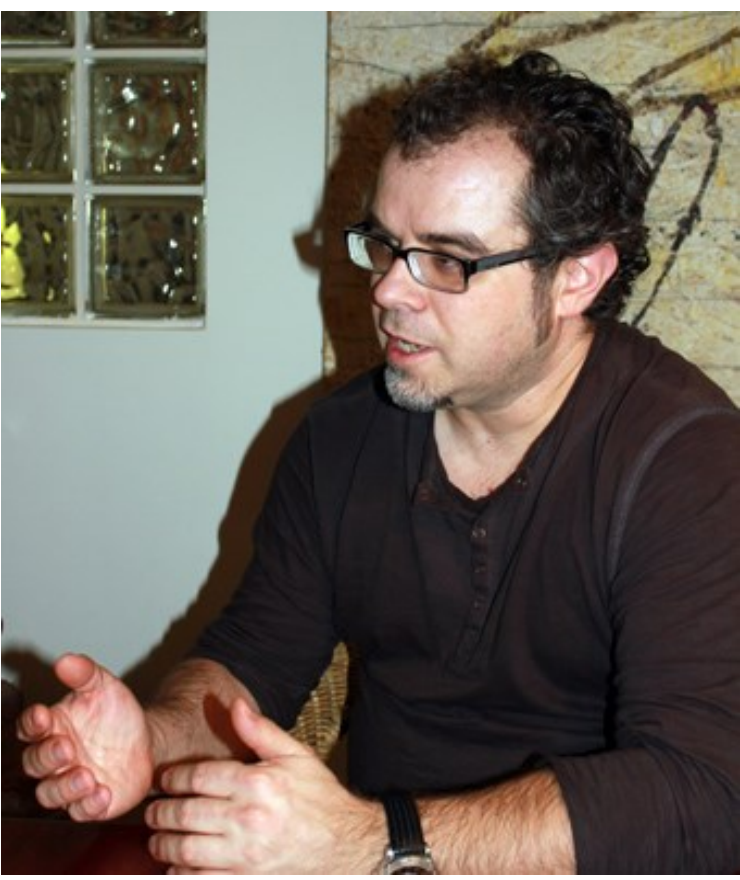

Arsenio Sánchez Hernanpérez plasmados en su amplísima producción escrita, en su labor docente desarrollada en numerosas escuelas y universidades y en sus contribuciones científicas a congresos y simposios.

Arsenio Sánchez inició sus estudios en la especialidad de Conservación y Restauración del Documento Gráfico en la Escuela de Artes Aplicadas y Oficios Artísticos de Madrid, Sección de Artes al Libro, especialidad que culminaría en 1998 con su diplomatura en la Escuela Superior de Conservación y Restauración de Bienes Culturales de Madrid. Unos años antes, en 1993, se había licenciado en Geografía e Historia, con la especialidad de Prehistoria y Etnología. Desde 1988, año en que se graduó en la Escuela de Artes Aplicadas, comenzó su andadura como restaurador de libros y documentos, primero en el Instituto del Patrimonio Histórico Español (actual IPCE), después en el Museo Nacional del Pueblo Español y por último en la Biblioteca Nacional, donde trabaja con carácter fijo desde mayo de 1992. Pero su curriculum vitae tiene otro capítulo importante en la labor docente, desde su participación como profesor de la Escuela Universitaria de Biblioteconomía y Documentación de la Universidad San Pablo CEU de Madrid, a sus numerosísimas colaboraciones en master universitarios (UCM, Autónoma de Madrid y Carlos III entre otras), cursos nacionales y seminarios internacionales, con los que ha viajado a diferentes países de Iberoamérica para impartir cursos y conferencias sobre preservación de patrimonio documental. En la Biblioteca Nacional ha comisariados dos exposiciones: la primera en 2012, La química de los libros: Ciencia y 
conservación del patrimonio documental, y la segunda, entre marzo y mayo de 2013, Piel Sobre Tabla: encuadernaciones mudéjares de la Biblioteca Nacional, en colaboración con Antonio Carpallo Bautista.

Por último, queremos destacar uno de los trabajos a los que él se siente ligado de una manera especial, el proyecto internacional para la "Dotación e instalación de los talleres de Restauración y Encuadernación de la Biblioteca Universitaria de Bosnia Herzegovina en Sarajevo, un proyecto que coordinó desde la ONG Paz Ahora entre agosto de 1999 y octubre de 2001, subvencionado por la AECID. Con este tema, clave en su trayectoria, comenzamos la entrevista.

\section{Entrevista}

Pregunta: La magnitud del desastre patrimonial y la tragedia humana que pudiste conocer de primera mano en la capital bosnia tras la guerra ¿ha marcado tu visión de lo que debe ser la conservación del Patrimonio Cultural?

Arsenio Sánchez: Este proyecto me obsesionaba desde que vi la destrucción de la Biblioteca, casi en directo, en los noticiarios televisivos del 25 de agosto de 1992. El conflicto bosnio había estallado meses antes y ya se empezaba a hablar de limpieza étnica y de memoricidio. La guerra, de carácter nacionalista, pretendía imponer una cultura sobre otras. Sí, hubo destrucciones con intereses estratégicos y económicos claros, pero con la destrucción de los censos de población del siglo XIX, de Vijecnica -sede de la biblioteca- o de las mezquitas de Foca, se trataba de destruir el patrimonio del enemigo, las culturas "extrañas", los símbolos, la composición multiétnica de Yugoslavia y todo lo que ello representaba. En 1998, Julian García, Villalobos, que preparaba un proyecto para la O.N.C.E. en Mostar, contactó conmigo y me ofreció la posibilidad de trabajar en la Biblioteca. Algunos meses después ya me había documentado, e incluso había empezado a estudiar el fenómeno del memoricidio como parte de los proyectos genocidas en sistemas totalitarios y creía estar

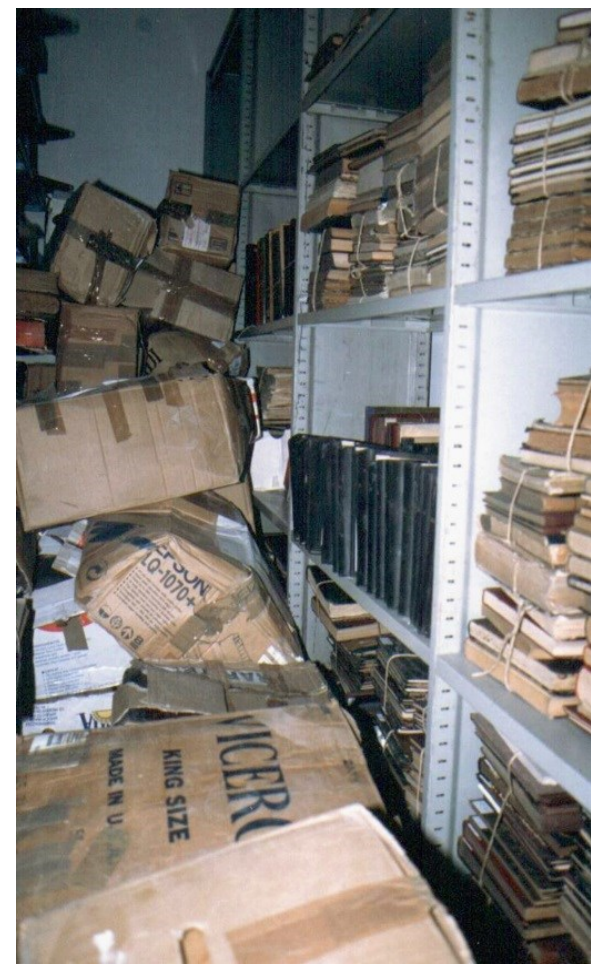

Parte del material bibliográfico recuperado después de la destrucción espera ser procesado en los nuevos depósitos de la BNUBH en Sarajevo. O2013. Arsenio Sánchez. preparado para verlo de primera mano. Sin embargo, la realidad fue mucho más dura de lo que había imaginado. En junio de 1999 hice mi primer viaje. Para salir del aeropuerto de Sarajevo hay que atravesar el barrio de Dobrinja uno de los frentes más duros de la guerra. La destrucción allí era especialmente brutal: casas enteras destruidas con armas cortas, huellas del impacto de obuses en muros y en el propio aeropuerto y, algo que me impactó especialmente, los destrozos de la metralla. A pesar de los niños jugando en la calle, la sensación era angustiosa, y, lo peor es que ese sentimiento no paraba de crecer cada día. Así, de pronto empecé a preguntarme qué hacía yo allí, un restaurador de bienes culturales que no paraba de hablar de reconstruir una biblioteca cuando la gente malvivía en casas con paredes y techos de plástico. Empecé a sentir vergüenza y una sensación terrible de ridículo: yo venía a restaurar 
manuscritos cuando las mujeres de Sbrenica aún lloraban a sus muertos o en Sarajevo había colas de gente esperando horas para recibir una ración de comida. Dos años después, cuando terminamos el proyecto, me di cuenta que tal vez no me había equivocado tanto y que la cooperación podía contribuir a salvar los símbolos que permiten vivir a la gente en sociedad y a sentirse personas.

P.: Son sus señas de identidad y verlas reconstruidas es un alivio para ellos. Es la forma en la que nosotros como restauradores podemos contribuir a mejorar la sociedad, porque es lo que sabemos hacer. Tú llevas participando desde hace años con bomberos del Grupo Español de Ciudades Patrimonio de la Humanidad. Cuéntanos algo de esta experiencia.

A.S.: Se trata de una iniciativa de los principales parques de bomberos de las ciudades declaradas por UNESCO Patrimonio de la Humanidad en España. Hay representantes de Cuenca, Santiago de Compostela, Toledo, Ávila, Ibiza o Córdoba entre otras. Muy concienciados con la importancia del patrimonio de sus localidades, empezaron a trabajar solos sobre cómo actuar en caso de desastre en los lugares patrimoniales. Apenas tenían información y por ello solicitaron ayuda al Ministerio de Cultura y otros organismos como el Museo Guggenheim de Bilbao, la Biblioteca Nacional de España, el Instituto de Patrimonio Cultural Español o el Cuerpo de Bomberos de Colonia. Está siendo una experiencia modélica, pues los conservadores podemos trabajar con todo el conocimiento de los expertos en situaciones catastróficas $y$, a la vez, ellos se benefician de las informaciones técnicas que restauradores, facultativos de museos, archivos y bibliotecas. Hemos realizado grandes simulacros en Segovia, Toledo o Tenerife y, a la vez, estamos colaborando con otros países en proyectos europeos -HeriProt- o formando a bomberos de Valparaíso o de La Habana.

P.: Representas una de las voces críticas más atinadas dentro de nuestra profesión. Tu interés por desmitificar aflora siempre en tus escritos, no hay más que ver algunos títulos de tu bibliografía. En uno de ellos, publicado en el año 96, "Paradigmas conceptuales de conservación", ya hablabas sobre cuestiones que hoy podemos seguir planteándonos con la misma actualidad, como la inadecuación de las políticas de conservación del Patrimonio, o el mito de la objetividad en la restauración y la restauración científica.

A.S.: Ahora pienso que son trabajos de juventud, que pecan de ingenuos, y me sonrojo al releerlos, pero estoy orgulloso de ellos. Empecé a pensar la profesión desde un punto de vista crítico. Siempre me ha gustado ser un iconoclasta y desmontar los mitos a los que nos aferramos. Por ejemplo, algo que comentaba en ese artículo era el proceso de nacimiento de la restauración científica -que yo llamaba ortodoxa por ser reconocida como buena por la comunidad de restauradores-, algo que se ha santificado durante muchos años y que se ha consagrado como la entrada en la mayoría de edad de la conservación de bienes culturales. Con ello, el debate ideológico -y aún el técnico-, parece haberse diluido. Hoy en día hablamos de resultados aportados por las técnicas instrumentales en el análisis de los materiales, pero ya no hablamos de procedimientos manuales ni de la maravillosa carga artesanal del restaurador antiguo. Se ha perdido la parte más simbólica en pos de ese cientifismo cuyo reflejo es una abrumadora cantidad de publicaciones basadas en análisis instrumentales pero muy pocas que describen técnicas o procesos de restauración. Mi impresión es que los restauradores de Patrimonio Histórico nos encontramos hoy encorsetados entre la obligación de restaurar obras del pasado, resultado de un proceso generalmente artesano $-\mathrm{y}$ por tanto eminentemente subjetivo- y la pretendida objetividad del trabajo "científico". Pero un trabajo científico no es solo "mirar por un canuto", como decía en tono iconoclasta Ortega y Gasset de Ramón y Cajal: lo importante no es el 
microscopio, sino el señor que está detrás de él y la interpretación que hace de lo que observa. En ese sentido los restauradores hemos dejado de interpretar porque nos resulta más fácil confiarlo todo a las máquinas. Nunca negaré que conocer los procesos químicos o cómo funcionan los materiales es fundamental para el restaurador, pero de ahí a que sea el objeto de la Restauración... tal vez hemos confundido el método con el objetivo

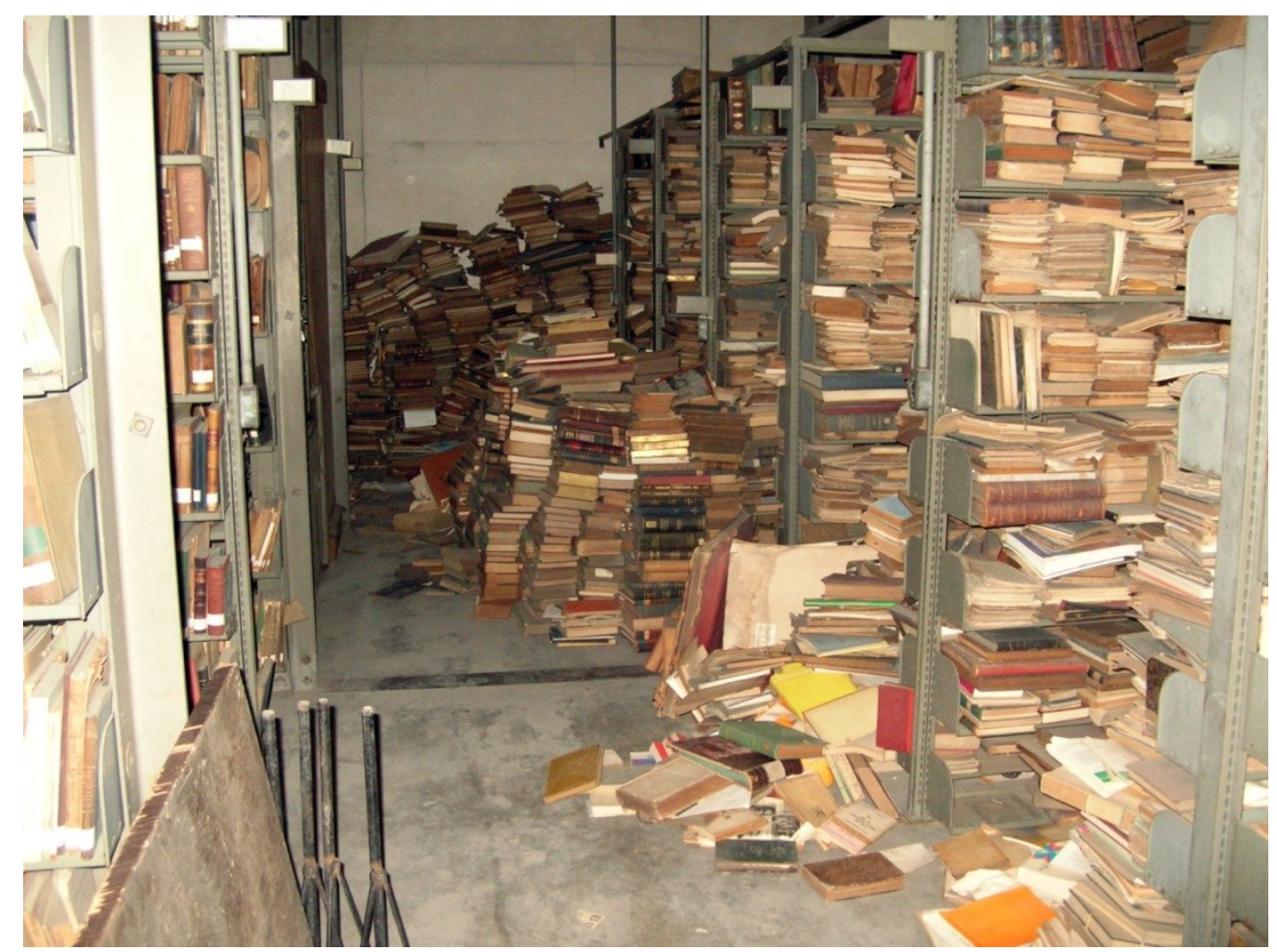

El gran desafío de la conservación en situaciones calamitosas. @2013, Arsenio Sánchez.

P.: Más bien menospreciamos ese tipo de trabajos, los consideramos signo de inmadurez. Pero recientemente el ICCROM ha distribuido una encuesta para conocer el acceso real de los restauradores a resultados de investigaciones científicas aplicadas a la restauración, y la valoración de este colectivo sobre su utilidad en sus prácticas. ¿No encuentras que hay una distancia enorme entre lo que se investiga y nuestra práctica real?

A. S.: En parte, la investigación es así. El problema es que nos encontramos todavía con muchos vacíos de información o que no siempre llega con la velocidad que quisiéramos. Por ejemplo, la desacidificación masiva del papel comenzó a estudiarse a principios de los 70 y la Biblioteca del Congreso ha empezado a utilizarla a escala industrial después de 20 años de experimentación. Ahora estamos trabajando en un proyecto del Instituto de Investigaciones Agrarias (INIA) en el que participa la Biblioteca Nacional de España para desarrollar bacterias generadoras de celulosa cristalina, de gran calidad, para refuerzo de las fibras de papel. Se han hecho grandes avances, pero quizá pasen años hasta que se puedan aplicar. Pero no siempre es así: un ejemplo de investigadora que tiene muy claro cuál es su profesión y que nunca pierde de vista las necesidades de la práctica real de la conservación es Nieves Valentín. Sus publicaciones siempre tienen una utilidad real. Cuando empezó a investigar con atmósferas inertes se ridiculizaron sus aportaciones, pero hoy son estándares internacionales en desinsectación de bienes culturales. 
P: Sin embargo, el desafío actual no reside tanto en los avances tecnológicos, sino en saber mirar a nuestro alrededor, abordar la conservación del Patrimonio desde el reconocimiento de su significado para la sociedad, sus valores culturales, en lo que entran a juego otro tipo de análisis, sociológicos, antropológicos, económicos...

A.S.: Sí, hay que analizar la carga cultural de lleva cada objeto. ¿Quién es propietario de la obra de arte? Un colectivo determinado. Pienso que la imagen del Patrimonio como tótem de la civilización no es buena porque aleja al ciudadano de la cultura y restringe su acceso a las élites. El ciudadano tiene que sentir que el Patrimonio forma parte de su vida y que puede acercarse a los grandes tesoros patrimoniales porque el Estado garantiza ese acceso. Debemos entender que el patrimonio no es algo propio de élites sino objetos reales que forman parte de nuestra vida cotidiana: en los momentos en los que Bach estaba componiendo el preludio de la primera Suite para violonchelo tal vez se estaba ahorcando a un pobre infeliz en una plaza de Cöthen. Ambos acontecimientos son parte de la vida misma y debemos aceptar que el mundo está lleno de contradicciones. Creo que uno de los problemas que hemos tenido los restauradores es que transmitimos esa idea equivocada del pasado a través de nuestro trabajo. Yo escribí hace muchos años que las restauraciones que se realizaban intentando estrechar los lazos que unían la obra con la sociedad no tenían por qué ser ilícitos, aunque chocaran con nuestros criterios de intervención. La gente de Borja está orgullosa porque desde hace dos años su localidad se hizo famosa por una desafortunada intervención restauradora. Hoy los habitantes de la ciudad están mucho más unidos a su Ecce Homo que lo había estado hasta entonces. Desde nuestro conocimiento académico y formal de restauradores eso nos choca, nos disgusta, pero hemos de admitir que nunca habría saltado a la fama con una intervención ortodoxa.

P.: Es indudable que ya es un icono para mucha gente, ha trascendido de ser una simple restauración burda a un hecho cultural, nos guste o no.

A.S.: No llega a restauración burda, como mucho, grotesca. Nosotros, en cambio, no hemos logrado conectar con los ciudadanos de igual modo. Parece que en ese lamentable caso, la acción de los medios de comunicación y la necesidad de dar "espectáculo" hace que trascienda no como un esperpento irrepetible sino como un hecho cultural relevante. A mí me gustaría que mis trabajos de restauración pasaran a formar parte del equipaje cultural de los ciudadanos, que se identificaran con las obras tratadas y que se apropiaran de sus valores, pero lo veo muy difícil.

P.: También podemos encontrar en las ciencias sociales otro tipo de herramientas que nos facilite información para nuestros múltiples interrogantes, como, por ejemplo, parámetros de evaluación para medir los riesgos y la calidad de los tratamientos.

A.S.: Efectivamente, la respuesta no es única ni simple y cualquier solución en conservación requiere análisis complejos. Por ejemplo, la importancia de un libro ¿cómo se valora? ¿Está en la portada o en el bloque de texto? Pues depende de a quien preguntemos. Para el estudioso estará el bloque de texto, pero para el bibliotecario, probablemente en la portada... ¿Qué es lo que tenemos que medir para cuantificar la pérdida del valor de un libro? ¿Una hoja, un colofón, la función de la encuadernación? Al final medimos de forma subjetiva, que es una de mis obsesiones: la subjetividad del restaurador.

P.: Pero la subjetividad no tiene por qué ser mala, lo importante es la actitud crítica y argumentada del restaurador. 
A.S.: No, ¡si yo la defiendo! El restaurador tiene que ser subjetivo al tomar decisiones, y aceptar que las está tomando. ¿Miramos por un canuto y ya está? Seguimos necesitando ese instrumento que permita diferenciarnos de los malos artesanos o de la señora del Ecce Homo de Borja. La diferencia está en la forma de pensar los problemas y las soluciones. Todos queremos pensar en términos absolutos, nos gustaría que nos dijeran "este manuscrito, en estas condiciones de HR y T va a desaparecer en 35 ó 40 años", pero la realidad nos ha demostrado que no es así de sencillo. Nuestros códices han estado en condiciones lamentables durante siglos, han pasado guerras y, sin embargo han llegado hasta aquí.

P.: Esa idea es un arma de doble filo, una justificación para la administración o los tutelares de que no hay que hacer nada...

A.S.: En absoluto, el Estado debe mimar su patrimonio porque es delicado y tiene grandes necesidades. Miro con envidia el desarrollo de la conservación en las instituciones documentales inglesas, holandesas o norteamericanas, pero su situación no es casual: las administraciones de aquellos países consideran sus bibliotecas y archivos como joyas culturales a las que deben alimentar y proteger. Algo que no me cuadra del caso español es por qué se conceden presupuestos generosos a los grandes museos y se abandonan a los grandes archivos y bibliotecas. La explicación puede estar en esa idea de la sociedad española de que las bibliotecas y archivos son lugares grises a los que van personas muy aburridas. Ello nos lleva a su desaparición o en el mejor de los casos, a la estrangulación económica. Tenemos importantes instituciones documentales al borde del colapso por la falta de medios, personal e instalaciones adecuadas. Creo que el problema es de base, y de una educación que no valora el patrimonio cultural en términos de desarrollo sino sólo como fuente de ingresos, la conservación no será una exigencia de la sociedad, sólo un reclamo turístico.

P.: Cómo va a prosperar que el Estado se haga cargo de la conservación del patrimonio, cuando además en estos tiempos se está negando a los ciudadanos servicios y necesidades básicas como la vivienda, la sanidad, la educación... Tenemos que buscar otras vías. Un ejemplo admirable de participación de los ciudadanos en la salvaguarda y conservación de su patrimonio cultural y paisajístico es el National Trust de Reino Unido, ¿cómo interesar a los ciudadanos por la Conservación de su Patrimonio Cultural?

A.S.: Tiene que ver con el papel que el patrimonio juega para el ciudadano. Esa es otra diferencia del patrimonio bibliográfico respecto a otros. Éste es un patrimonio accesible, que se usa, se toca y se manipula, y esa debería ser una de nuestras ventajas, aunque desgraciadamente se ha convertido en todo lo contrario, pues ha llevado a su trivialización. Debemos convencer de su valor y de la importancia de cuidarlo y enriquecerlo.

P.: Eso te ha llevado en muchas ocasiones a plantearte otros criterios de restauración.

A.S.: Una de las ideas clásicas más incompatibles con la conservación del patrimonio documental es que el restaurador tiene que llevar la obra a su estado original. Ello no nos sirve a los restauradores de documentos: la obra tiene una vida, ha sido transmitida de propietario a propietario y cada uno ha ido aportando variaciones, anotaciones, mutilaciones, cambios de encuadernación..., todo esto nos habla de cómo se ha ido transmitiendo ese conocimiento, y a su vez el deterioro ha ido añadiendo información al objeto. Por tanto, cuando restauramos patrimonio documental tenemos que intentar compatibilizar las necesidades de conservación del ejemplar con toda la información que enriquece al ejemplar. Por ejemplo, al fijar la liturgia católica 
en el concilio de Trento, se establecieron los cantos para cada la época del año. Los mismos cantorales se van a usar durante siglos y las manipulaciones y deterioros te indican de cómo se han utilizado. En cada biblioteca te encuentras particularidades. Sin embargo, una práctica de restauración muy común en el pasado fue eliminar todas las huellas de uso. ¿Debemos eliminar esa información?

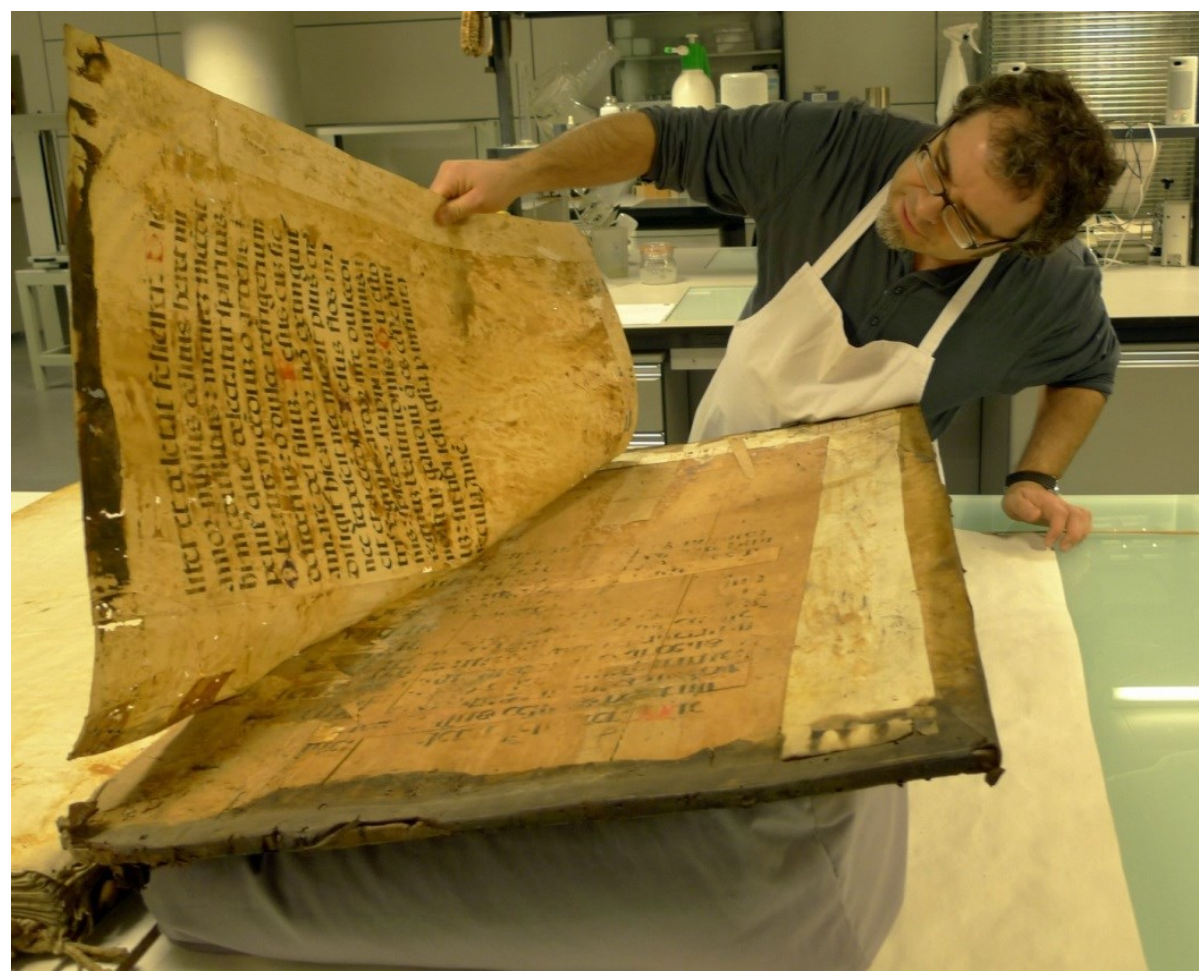

“¿Es posible un criterio universal de restauración? Tal vez, el único criterio de intervención universal sea la búsqueda 'introspectiva', el análisis de la propia personalidad del objeto, lo que es y lo que representa".

P.: Nuestra labor como restauradores se dirige al objeto físico que supone el libro. Nos interesaría saber lo que opinas sobre las bibliotecas del futuro, lo bueno y lo malo que pueden traer.

A.S.: Las bibliotecas están en un momento de crisis importantísimo. Desde los años 70 hubo que redefinir su papel en la sociedad y empezaron a ofrecer nuevos servicios a los usuarios, servicios que eran gratuitos. Pero a partir de los años 90 se comenzó a cuestionar la gratuidad del acceso a esa información y se estableció la obligación de pagar derechos de autor, lo cual me parece casi tan trágico como el hecho de que haya que pagar para entrar en un museo. El caso es que ahora mismo, con las nuevas tecnologías de la información, es mucho más fácil acceder a los contenidos de las bibliotecas y podemos leer la primera edición del Quijote en un Ipad a la vez que hacemos spinning en un gimnasio. Es un proceso que viene de lejos, en concreto desde los años 80 del siglo XX, cuando comienza la era del terror al papel ácido y las bibliotecas se lanzan a reproducir todo lo que creen que van a perder entes del siglo XXI. Actualmente, las bibliotecas digitales han sustituido a las bibliotecas tradicionales gracias a la mayor calidad $y$, sobre todo a la facilidad de acceso. Hoy es posible universalizar el acceso a la información, lo que supone uno de los mayores avances de la sociedad contemporánea, un proceso tan importante como la revolución industrial en el siglo XIX. Pero no todo es luz. En esa carrera de las instituciones hacia la reproducción de los contenidos se 
corre el riesgo de realizarse sin un análisis de lo que tienen que ofrecer esas bibliotecas digitales y, por tanto, de malgastar los recursos económicos: la Biblioteca Nacional no será mejor biblioteca digital por el hecho de ofrecer millones de páginas, sino porque sus páginas reproducen fielmente aquello que la han convertido en una de las diez bibliotecas más importantes del mundo: un extraordinario conjunto bibliográfico que representa fielmente qué es España y que ha aportado a la cultura universal. Esto en ocasiones se ha olvidado y la falta de coordinación entre las bibliotecas españolas ha llevado a que puedes encontrar en la red el mismo periódico en cuatro versiones digitales distintas. Es decir, el ciudadano ¡ha pagado cuatro veces por lo mismo! Eso es trágico si pensamos en déficit de los recursos que tienen las bibliotecas y archivos hoy día. Se están gastando en unas políticas que yo no dudo que sean bienintencionadas, pero no deja de ser, cuando menos superfluo.

P.: Cuando la gente ve esos almacenes atestados de libros y legajos piensa que la digitalización es la solución.

A.S.: Se tiende a pensar que el archivo digital sustituye al documento material, que lo digital no ocupa tanto espacio como el libro físico y, por tanto, cuesta menos conservarlo. Sin embargo, conservar la documentación digital es infinitamente más costoso que la conservación material de libros. La biblioteca del Congreso de EEUU calculó a principios de los 90 que el coste de preservación de un libro de 700 páginas en una caja era de 7 dólares, y que su conservación en formato digital de preservación y alta calidad tenía un coste aproximado de 3500 dólares en 100 años. La regla es sencilla: hay unos costes de digitalización -entre los que no vamos a incluir los costes de preservación del documento original, ni siquiera los de restauración del documento después de haber sido digitalizado, que eso es otro asunto-, y generas un archivo. Pero el coste de la digitalización no acaba ahí, el archivo tiene una permanencia limitada que es necesario actualizar mediante cambios de soporte, de formato o incluso emulando cuando los lenguajes quedan obsoletos. Por otra parte, a medida que se ingresan archivos en los servidores de la Biblioteca, es necesario, actualizar los equipos que deben gestionar archivos muy pesados a gran velocidad con cientos de demandas simultáneas, lo que exige sistemas informáticos cada vez más complejos y costosos. ¿Cuándo cuesta un sistema que gestiona 600 Tbs en línea? Es incalculable, conlleva gastos de mantenimiento de equipos, del personal que los manipula, la propia sala donde se conservan los equipos, la sustitución de componentes obsoletos. Y además, las bibliotecas tienen que ofrecer también otros servicios de información, como el acceso al catálogo, a bases de datos de pago o incluso a exposiciones virtuales y otras actividades. Nos hemos dejado arrastrar por los cantos de sirena de la digitalización y no hemos calculado los riesgos: dependencia de las empresas de software, crecimiento ilimitado del coste de la preservación digital y, como efecto derivado, la desaparición de la conservación material.

P.: Pero desde nuestro punto de vista ¿Qué significa esto? ¿Es que ya no necesitaremos las colecciones materiales de las bibliotecas?

A.S.: No, todo lo contrario. En un comercio, al comprar pagas con una tarjeta de plástico, haces uso de dinero virtual, que no ves, pero ese dinero debe existir en la caja fuerte de tu banco para que se autorice la transacción. En cierta medida, las bibliotecas y archivos son la caja fuerte de la información. Los libros físicos se guardarán en las bibliotecas mientras que la gente hará uso virtual de sus contenidos. Y tener una buena colección indicará la riqueza de tu banco.

P.: Con toda esta fiebre por la digitalización ¿se dedican menos recursos a la conservación documental? 
A.S.: Desgraciadamente si o, al menos, en el caso español. Nos estamos relajando en la conservación material del patrimonio documental y creo actualmente estamos peor que en el siglo pasado. Pero esto no es un problema universal. Las bibliotecas líderes en digitalización y recursos electrónicos son anglosajonas. Ellas imponen el modo en que se debe digitalizar, pero también las condiciones de conservación material porque han transitado previamente por el camino de la conservación material, aplicando métodos y criterios modernos durante mucho tiempo. En nuestro país, en cambio, hemos pasado de no hacer nada a intentar digitalizar todo y nos hemos saltado todo el proceso de entender qué es la conservación. El problema es que probablemente recurriremos a la conservación material cuando empecemos a ver las carencias de la información digital.

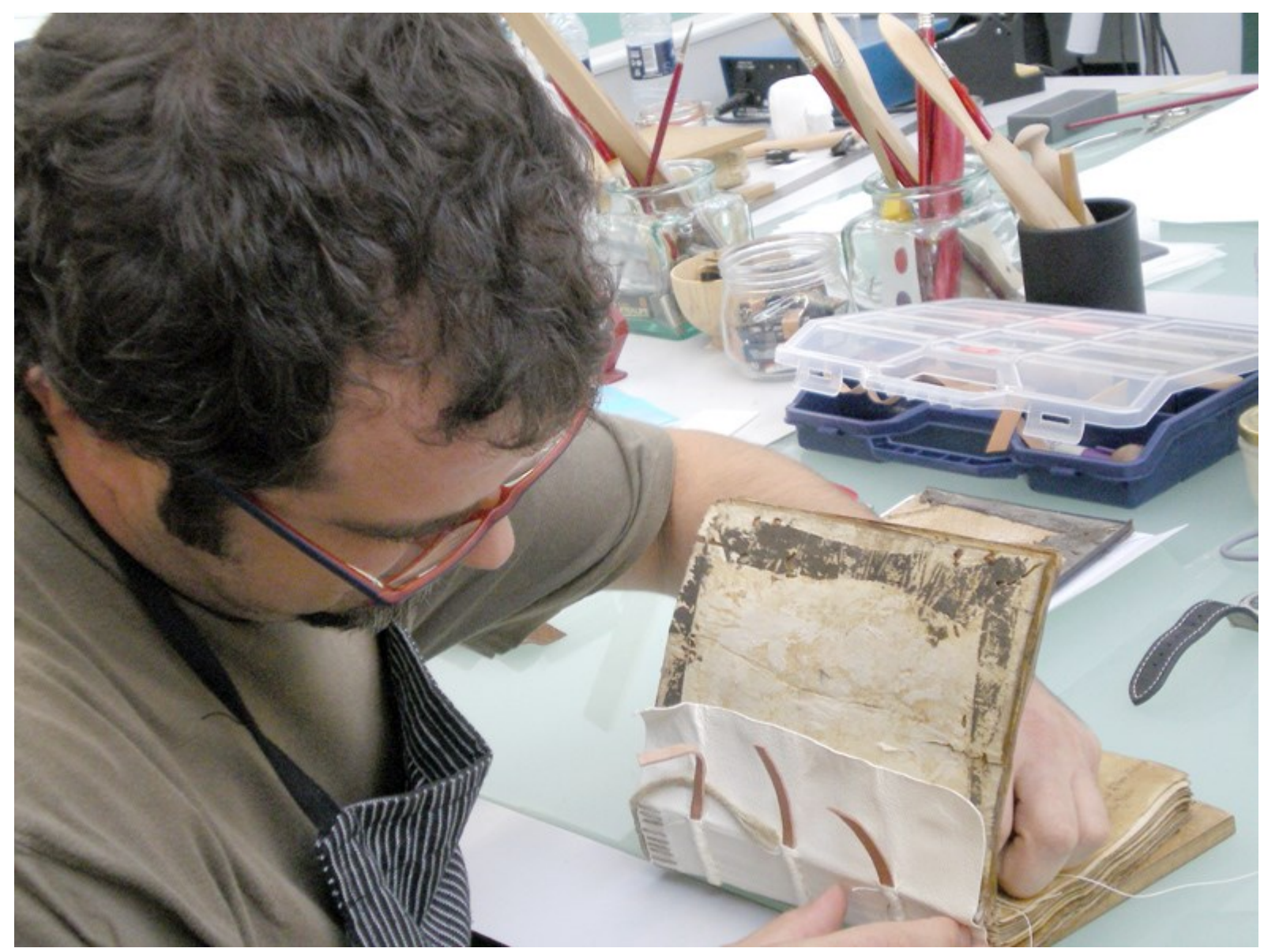

Costura del manuscrito original del Poema de Mio Cid. En su restauración se modificaron algunos elementos de la encuadernación del siglo XVI para mejorar su funcionamiento, aunque conservando el aspecto general.

P.: Hay que pensar que Estados Unidos tiene un acervo histórico y documental más corto.

A.S.: Eso no es cierto. Estados Unidos tiene el mayor patrimonio bibliográfico y documental del planeta, sólo se le acerca Reino Unido. En cualquier caso, ojalá tuviéramos en España los 200 últimos años de nuestra historia conservados de la misma manera. Nuestro país es uno de los líderes mundiales en la destrucción de su patrimonio. Los dos últimos siglos han sido terribles: lo 
hemos vandalizado, abandonado, expoliado, exportado ilegalmente, lo hemos destruido, y no contentos con ello, nos hemos vanagloriado de hacerlo. $Y$ no hablemos de situaciones en las que se entremezclan intereses económicos: los años 60 y 70, con el desarrollismo y la especulación inmobiliaria fueron tan catastróficos para el patrimonio arqueológico y arquitectónico como la Guerra Civil o la pobreza secular.

P.: Nos gustaría que hablemos de una cuestión que también afecta, y muy directamente, a la conservación del Patrimonio Cultural: la situación profesional y laboral de los restauradores. Estamos instalados en una precariedad que no es solo consecuencia de la crisis actual sino que viene de hace tiempo, a lo que se suma una falta general de reconocimiento y una aceptación resignada por nuestra parte de que la función del restaurador se reduce a la mera ejecución ¿Acaso no estamos preparados para dialogar en pie de igualdad con otras profesiones afines a la nuestra en el campo del Patrimonio? ¿Qué opinas sobre todo esto?

A.S.: No ayuda mucho la precaria situación laboral de los restauradores del Ministerio y de otras administraciones, donde los departamentos de restauración carecen de una dirección técnica o están dirigidos por el cuerpo de facultativos. La excusa es que somos técnicos y, por tanto, nuestro perfil se ajusta mejor al de contratados laborales. Ello produce una colisión de funciones entre los facultativos y los restauradores-conservadores y una rivalidad permanente entre ambos colectivos. Efectivamente, son dos parcelas complementarias, pero no podemos obviar grandes diferencias funcionales. A nadie se le ocurriría poner al frente de un departamento de Antigüedades Egipcias y de Próximo Oriente a un funcionario del Cuerpo de Gestión. ¿Por qué algunas instituciones como el Museo del Prado o el Reina Sofía sí han puesto al frente de sus departamentos de restauración a restauradores y el propio Ministerio de Educación Cultura y Deporte no lo admite en las demás instituciones? Si es bueno para instituciones punteras ¿por qué no es bueno para las demás? Es un misterio que se me escapa, pero está limitando increíblemente el desarrollo de una conservación moderna y eficiente en nuestro país.

P.: No ha habido voluntad política desde la administración por cambiar eso, han pasado muchos años desde que se puso en evidencia esa contradicción en nuestro medio profesional y se ha hecho muy poco para solucionarlo.

A.S.: Todo lo contrario, la tendencia es reducir su papel en la toma de decisiones. Cuando yo aprobé mi oposición tenía un nivel asimilado económicamente a titulado superior. El famoso Convenio Único en la Administración General del Estado se supone que habilitaba a los contratados laborales para dirigir departamentos de conservación, pero desde el año 98 no se ha creado ninguna jefatura entre los laborales dentro del convenio. Tampoco se han dotado económicamente los complementos específicos para los restauradores. En realidad fue el inicio de la decadencia de los restauradores en la Administración General del Estado. No obstante, existe una salida y pasa por que el Ministerio recurra a una figura poco conocida, el Cuerpo Técnico de Gestión, un grupo de funcionarios A1 que desarrollan funciones fuera de las habituales de ese grupo. Dado que sólo hay restauradores en el Ministerio de Educación, Cultura y Deportes, sería factible la creación de Cuerpo Técnico de Gestión de Conservadores-Restauradores de Patrimonio $y$ funciones de $\mathrm{A} 1$.

P.: Excepto los ejemplos que has mencionado, no hay en la administración central otros cargos de responsabilidad en conservación y restauración que estén ocupados por restauradores en calidad de su profesión como tal, ciertamente algunos tienen estudios en restauración, pero los méritos que les han llevado a conseguir esa plaza no son los de restaurador si no los de conservador de 
museos. Esto quiere decir que el restaurador encuentra su techo en la función práctica de su trabajo.

A.S.: Por eso se entiende que los restauradores estemos frustrados. A mí me gustaría pensar que tengo una carrera profesional en la Administración o, al menos en la institución para la que he trabajado más de 20 años. Si a veces he pensado en tirar la toalla y dedicarme a la enseñanza de Historia y Geografía en un Instituto de Secundaria ha sido al ver qué la inexistencia de promoción profesional en el ámbito de la restauración.

P.: Un reconocimiento que no sea de palabra solo...

A.S.: En una ocasión, un alto cargo del Ministerio de Cultura espetó a los investigadores del IPCE "ustedes no son personal investigador, son contratados laborales del Ministerio de Cultura". Esa frase es muy cruel, pero expresa una realidad. Nosotros no podemos aportar más porque nuestras instituciones están limitadas por las relaciones de puestos de trabajo y el Estatuto de la Función Pública. Pero no quiero que esto se confunda. Los restauradores somos profesionales bien reconocidos en general, lo que falta es una clasificación funcional que permita desarrollar la profesión dentro del ámbito de la administración. No sólo por una cuestión de modernidad, es que el patrimonio cultural lo necesita. Ello explica que los restauradores andemos tan...

\section{P.: ...tan desfondados...}

A.S.: Lo peor es que la situación, aparentemente, no va a mejorar. La tendencia actual es externalizar los servicios de restauración y a que las plazas de restauradores se vayan amortizando a

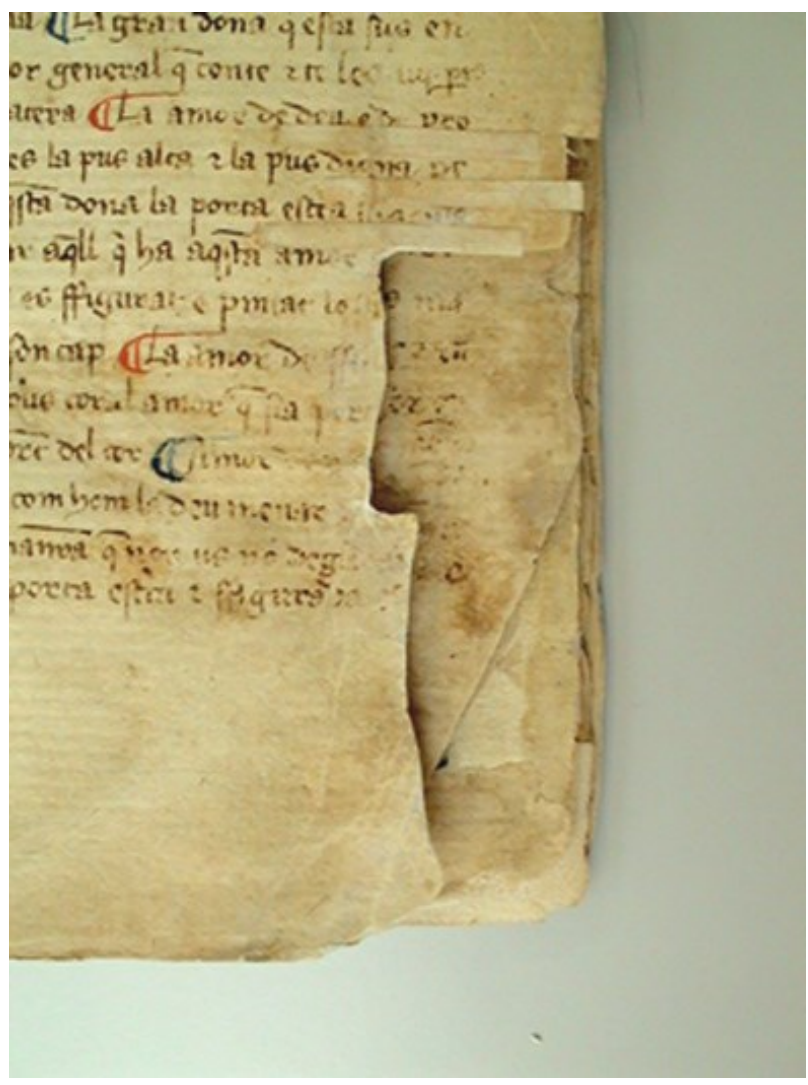

Detalle de la restauración del manuscrito Res/203 Breviario de Amor de la Biblioteca Nacional, en el que se emplearon criterios de mínima intervención y respeto absoluto por las modificaciones realizadas en los siglos XVII y XVIII.

@2013, Arsenio Sánchez. medida que se vayan produciendo jubilaciones. Serán los facultativos de archivos, bibliotecas y museos en su calidad de responsables de los servicios quienes decidan en qué piezas se va a trabajar, quiénes y cómo. $Y$ esto es un problema para la conservación del Patrimonio, porque nos lleva directamente al ámbito privado, donde la situación es también dificilísima y excelentes profesionales malviven para ganar concursos a la baja. Ya no se negocia la calidad de los proyectos, sino el precio que se va a pagar por ello. En el patrimonio documental la situación es aún peor: las instituciones no suelen tener servicios de restauración. Las bibliotecas de fondo antiguo con taller de restauración en España no deben ser más de diez, tal vez cinco. En el caso de los archivos, las instituciones con laboratorios 
bien montados probablemente sean alguno más, unos 15 ó 20, aunque algunos llevan años instalados sin que nadie haya trabajado jamás en ellos.

P.: Tener un departamento de restauración es un servicio caro, pero qué me dices del futuro, que es la Conservación Preventiva, y el presente para muchos países. ¿Cuántos instituciones dedicadas a la custodia del patrimonio en España tienen un departamento ad hoc para gestionar la Conservación Preventiva? En conservación de patrimonio documental habéis sido los primeros iniciadores en este tipo de prácticas ¿Cuál es la realidad actual de la Conservación Preventiva?

A.S.: La Conservación Preventiva surge como idea en los años 80 cuando se empieza a centrar la atención en las causas del deterioro documental y en su relación causa-efecto. Al principio se intenta desarrollar un enfoque que, a mi modo de ver, se centra especialmente en los números ya que entiende que el deterioro se puede controlar conociendo los procesos físico-químicos que lo causan. Como anécdota, en 1972 se publicó un artículo que trataba sobre la relación entre la temperatura de almacenamiento y el deterioro del papel en el que, basándose en ecuaciones termodinámicas, el autor concluía que cada $7^{\circ} \mathrm{C}$ se reducía a la mitad la esperanza de vida del papel. Incluía un cuadro que se convirtió en un clásico en el que los archiveros y bibliotecario -y también los restauradores- calculábamos cuantos años de vida le quedaban a un libro o un periódico según la temperatura a la que lo guardábamos.

Esa idea simplifica mucho la enorme complejidad que se da en los procesos físico-químicos relacionados con la temperatura, la humedad y la entalpía de alteración o energía que necesitan los materiales para deteriorarse. Claro, estamos en una sociedad un poco perezosa y, al final, lo que hacemos es simplificar y, trabajando en el control de humedad y la temperatura, creíamos que podríamos llegar a conservación prácticamente eterna. Eso nos lleva al falso silogismo de que unas condiciones de humedad y temperatura muy precisas nos garantizan la conservación a largo plazo. Esto no es del todo correcto porque no todos los materiales son iguales ni tienen la misma resistencia ante la humedad y la temperatura. Un mismo documento puede tener distintos materiales que pueden no reaccionar igual. Sin embargo, todos estos años hemos intentado sistemáticamente reducir la conservación preventiva al control de la humedad y la temperatura, de los contaminantes atmosféricos, las radiaciones electromagnéticas y la luz. Después fuimos ampliando a otros campos como el control de plagas y la gestión de desastres. Y así aparece el concepto de la gestión de riesgos en conservación preventiva, que nos ha llevado a una disciplina enormemente compleja para la que deben desarrollarse aún nuevos sistemas de análisis e interpretación.

P.: Esto nos lleva a uno de los últimos campos desarrollados por la Conservación Preventiva, la gestión de riesgos, en el que tú has trabajado ampliamente.

A.S.: Ahora mismo es uno de los campos más interesantes. Uno de sus iniciadores, el canadiense Robert R. Waller, se planteó un acercamiento a la gestión de riesgos valorando los elementos de deterioro, el volumen de daños en las colecciones y la frecuencia con la que los agentes afectaban en el material. Este enfoque fue después muy trabajado por el Instituto Canadiense de Conservación y en especial por Stefan Michalski que analizando qué elementos generaban deterioro, cuál era su impacto en los objetos y la pérdida de valor de la colección por el deterioro de esos objetos podría determinar una conservación preventiva y paliativa más adecuada a las necesidades de la colección. Para ello es necesario establecer una serie de ecuaciones bastante trabajosas aunque no demasiado complicadas. Esta forma de entender el deterioro me parece muy interesante porque sitúa en diferentes escenarios y facilita enormemente la toma de decisiones. En 
colecciones homogéneas permite establecer cuáles son los puntos en los que falla nuestro sistema de Conservación Preventiva. Por ejemplo, el uso de cajas acidas produce un deterioro químico en el papel, pero en una caja de archivo podemos meter hasta un volumen de hojas de $10 \mathrm{~cm}$ de grueso que, además, pueden ir guardadas en varias carpetillas; la cantidad de ácido que se trasmite desde la caja al interior viene filtrado por los documentos que están en contacto con la caja y por las carpetillas, con lo cual, la terrible agresión que trasmitirían las cajas se ve mitigada en parte por los documentos contiguos al cartón y en parte por las barreras que suponen los contenedores. Si tenemos en cuenta que un archivo se mide por kilómetros de estanterías -la Biblioteca Nacional tiene más de 400 km-; al hacer el ejercicio de gestión de riesgos veremos que las cajas ácidas generan daño a menos de una millonésima parte del fondo. Frente a ello, en los últimos 5 años se han hecho en la Biblioteca unas 60.000 cajas a medida necesarias para proteger de la manipulación y deterioro otros tantos volúmenes. Si pensamos que el coste de restauración medio sería de unos $200 €$, hemos evitado gastos por valor de $12.000 .000 €$ frente a una inversión realizada de unos $450.000 €$.

El problema es que la gestión de riesgos puede darnos buen resultado para colecciones homogéneas, pero cuando tenemos colecciones muy dispares, con valores muy diferentes el cálculo se vuelve muy complejo y farragoso.

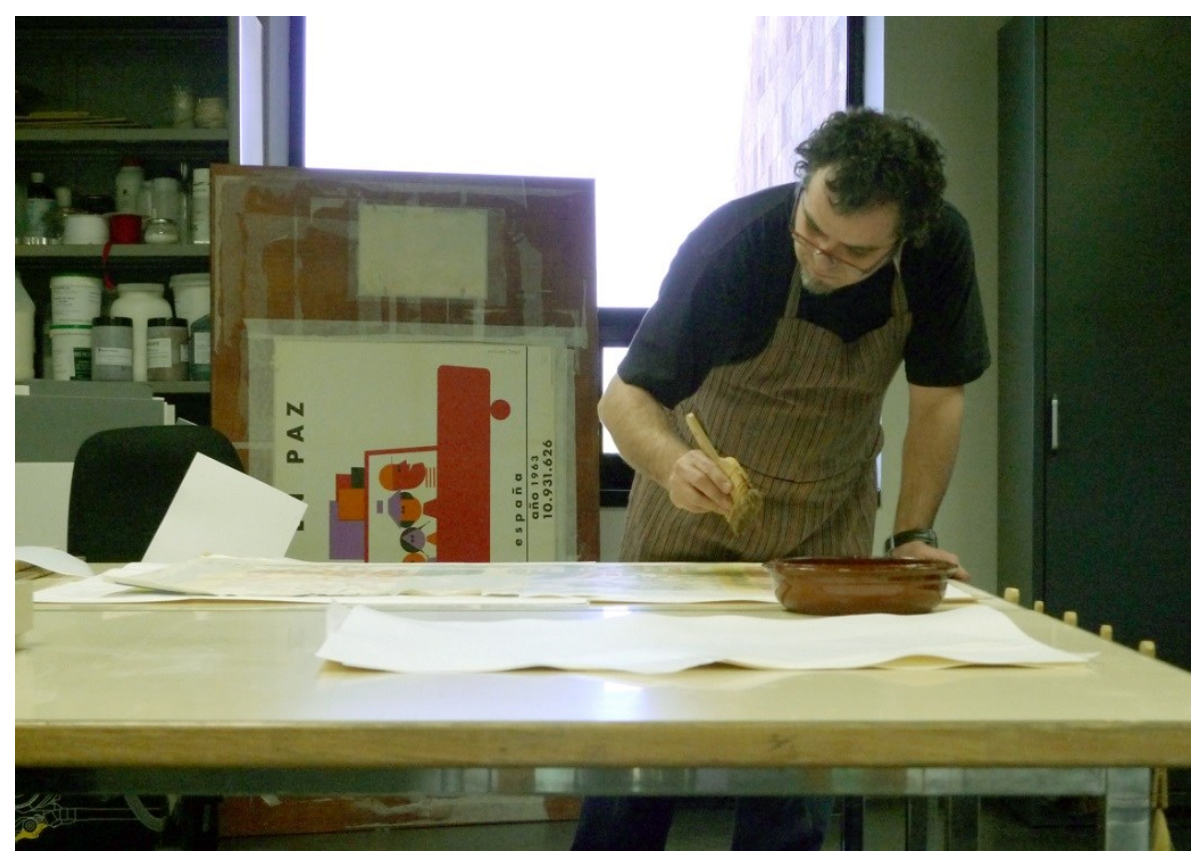

Analizando diferentes procesos de limpieza por capilaridad en el taller de la BNE en Alcalá de Henares.

P.: Una cosa es el sentido común y otra la instrumentación del sentido común. En ese sentido se entienden los diez agentes de deterioro defendidos por el ICC, que es una referencia indispensable en conservación preventiva.

A.S.: Me parece fascinante el método de conservación preventiva planteado por el Instituto Canadiense y sus diez fenómenos de alteración, aunque creo que en algunos casos se podrían reducir. Es un instrumento de trabajo poderosísimo, porque estructura y elimina el ruido que nos 
lleva a la dispersión en la conservación. Actualmente estoy trabajando en su adecuación a los archivos y bibliotecas y trato de delimitar los escenarios, pues el método se concibió para trabajar en museos. Lo interesante es que no todos los agentes están en los mismos escenarios y sólo debemos centrarnos en los que se encuentran presentes. Además el ICC fue más allá, porque aporta una solución basada en cinco pasos: identificar, bloquear, detectar, corregir, tratar, que, aunque también son discutibles, dan una guía excelente para elaborar planes de conservación por fases.

P.: Hace falta poner número a los resultados, quien toma las decisiones pide cifras.

A.S.: Sí, es necesaria la métrica de la conservación.

P.: Pero siempre chocamos con los intereses políticos, la falta de visibilidad de los resultados es un impedimento.

A.S.: Eso son riesgos de carácter externo que no puedes dominar: no puedo controlar que el político me haga caso, pero sí puedo plantear acciones más efectivas en términos de colección o la forma en la que comunico mis necesidades al responsable político. Creo firmemente en la conservación preventiva, mi experiencia me ha hecho percibir que la gente sí es consciente de su importancia. Mi primer paseo por los depósitos de la Biblioteca Nacional hace 22 años, fue una experiencia imborrable al ver las condiciones en las que se encontraban. Nada se parecía a lo que había estudiado. Pero la realidad es tozuda y hay que tener en cuenta que se trata de una institución longeva que lleva 300 años funcionando y que en todo ese tiempo no había existido conservación preventiva. Parar en seco una tradición secular y mejorar inmediatamente aplicando principios de conservación preventiva sería iluso, pues solo en el depósito general hay cerca de 6 millones de volúmenes y no es posible dar conservación a toda esa cantidad de libros en poco tiempo. Pero sí es cierto que en los últimos años se han dado grandes pasos: se ha creado un nuevo depósito en Alcalá de Henares que absorbe de manera ordenada el crecimiento del fondo, se han sustituido los sistemas de iluminación tradicional por dispositivos automáticos, se ha instalado un sistema de extinción y detección de incendios y los depósitos están limpios. Además se está desarrollando un plan de conservación de libros únicos y deteriorados que nos permite conocer el estado de los documentos más amenazados y se está encajando una media de 5.000 volúmenes al año. La realidad es que el cambio ha sido bastante notable y debemos seguir trabajando en esa línea, asumiendo nuestras dificultades y buscando alternativas viables.

P.: El trabajo es complicado y más teniendo en cuenta que no existen departamentos específicos de Conservación Preventiva. Dentro de empresas que se dedican a otros sectores profesionales hay departamentos que se dedican a la gestión de los riesgos laborales, en Patrimonio en cambio no existe esa lógica. Tú lo haces pero compatibilizándolo con la restauración, las investigaciones, las publicaciones y la docencia...

A.S.: Bueno, hay mucho que aprender y afortunadamente estoy en un sitio privilegiado. En cuanto a los departamentos de conservación preventiva, en la actualidad son una utopía en nuestro país. Hay pocos planes de formación, pero la administración no absorbe a los técnicos que se han formado. Pero en Iberoamérica, por ejemplo, el sistema de gestión de riesgos se ha desarrollado bastante hasta el punto que, en Ecuador, el gobierno declaró una emergencia nacional basándose en un estudio de riesgos de su Patrimonio Cultural. Esto es muy bueno porque la declaración de emergencia nacional implica que los recursos del estado se ponen al servicio de los gestores del patrimonio. 
Uno de los problemas de la conservación preventiva es lo abstracto de su aplicación. Los cinco pasos del ICC son lentos y es posible lograr resultados más rápidamente mediante la aplicación del método de las cinco " $\mathrm{S}$ ", un método de trabajo desarrollado en una de las factorías japonesas de Toyota para generar espacios de trabajo productivos. Se basa en 5 principios básicos que son ordenación, disciplina, orden, limpieza y normalización de las cuatro anteriores. Estoy trabajando con este método para ofrecer una aplicación sencilla de la conservación preventiva en archivos y bibliotecas. La idea me la dio Juan José Prieto, un experto en seguridad en bibliotecas. Muchas veces pensamos que el Patrimonio es algo diferente de la realidad cotidiana, pero los archivos, bibliotecas y museos no dejan de ser espacios de trabajo y la limpieza y el orden son dos puntos fundamentales. No podemos pretender ir hacia la CP si no hay limpieza ni que no haya accidentes si no hay ordenación del espacio. Son líneas de trabajo que van surgiendo a medida que se van clarificando los campos en los que tenemos que trabajar: Los trabajos del ICC y el sistema de las $5 \mathrm{~s}$ crean un tándem extraordinario con magníficas posibilidades de aplicación.

P.: ¿La Conservación Preventiva es la respuesta a la conservación del patrimonio documental, esa "tortuga difícil de alcanzar", como decías en alguno de tus artículos?

A.S.: En los años 70 y 80, con las inundaciones de Florencia y el comienzo del "terror acido" se empezó a ver que el papel se deteriora a una velocidad enorme, esto despierta una disyuntiva entre lo que hay que salvar y lo que no. No podemos restaurarlo y conservarlo todo. La respuesta son los planes de Conservación Preventiva, la creación de documentos que generen directrices con las que se debe trabajar, protocolos de trabajo, recomendaciones de conservación para cada tipo de material, y el control de los riesgos que generan el deterioro. Para mí Conservación Preventiva no es solo lo ortodoxo, lo oficial, si me permitís el término. Muchas veces estamos pensando en cajas de conservación para un archivo en el que las estanterías están deformadas o los documentos en el suelo. De ahí viene la paradoja de María Antonieta que proponía en uno de mis artículos. Dicen que en los momentos previos a la Revolución Francesa, una de las revueltas por la carestía del pan llegó hasta las puertas de Versalles. Maria Antonieta, preocupada por la algarabía preguntó el motivo de tal desorden y un ministro le comentó "Protestan porque no pueden comer pan", a lo que ella contestó, "si no pueden comer pan, que coman brioches". Ese es para mí el objetivo al que debemos llegar en conservación preventiva, dejar de recomendar brioches a quienes no pueden comprar pan...

\section{Bibliografía destacada}

\section{Libros:}

Desastres en Archivos: Como planificarlos. Gijón: Trea. 2011.183 págs.

Políticas de conservación en bibliotecas. Madrid: Arco Libros. 1999. (Instrumenta bibliológica).

Capítulos de libros y artículos:

"Documentos en exposiciones: Control de su deterioro", en Exponer documentos: Diseño y producción de muestras documentales, editado por Luis Hernández Olivera. Salamanca: ACAL, 2010, págs. 153-182.

"Después del Infierno: Reconstrucción y tareas pendientes", en Biblioteca en Guerra editado por Blanca Calvo Alonso-Cortés, Madrid; Biblioteca Nacional, 2005, págs. 389-406.

"Libri sine asseribus. Criterios de intervención en las estructuras de encuadernación flexible de los siglos XIV y $\mathrm{XV}^{\prime \prime}$. En Criterios de Intervención en la Restauración de Libros y Documentos. Pamplona: Archivo General de Navarra, 2008, págs. 179-190. 
Los soportes tradicionales y tecnológicos: Conservación y protección, métodos y medios, en Vencer al Tiempo: Conservación e instalación de los documentos municipales: Actas XVI Jornadas de Archivos Municipales, Consejería de Cultura y deportes de la Comunidad de Madrid/Ayuntamiento de Alcobendas/Grupo de Archiveros Municipales de Madrid, 2006, pág. 239-260.

"El códice Breviario de Amor y el concepto de mínima intervención en la restauración de documentos", en Roig Picazo, Pilar et.al. (eds.), 16th Internacional Meeting on Heritage Conservation Preprints of the papers to the Valencia Congreso, Valencia: Universidad Politécnica de Valencia, 2006, págs. 89-104.

"Paradigmas conceptuales en conservación", en CON•TACTO, Revista del Laboratorio de Restauración del Archivo General de la Nación, Colombia, 1996, nº especial 4-5, págs. 3-18.

\section{Exposiciones:}

"Piel Sobre Tabla: encuadernaciones mudéjares de la Biblioteca Nacional de España". Exposición realizada en la Biblioteca Nacional de España. Marzo-Mayo de 1013.

Exposición virtual en:

http://www.bne.es/es/Actividades/Exposiciones/Exposiciones/exposiciones2013/encmudejares.html?pagina=0

Catálogo en pdf interactivo disponible on line en:

http://www.bne.es/media/Micrositios/Guias/encuadmudejares/EncuadernacionesMudejares.pdf

"La química de los libros: Ciencia y conservación del patrimonio documental". Exposición realizada en el Museo de la Biblioteca Nacional de España. Noviembre-Enero de 1012. Catálogo disponible on line en: http://www.bne.es/es/Actividades/Exposiciones/Exposiciones/Exposiciones2011/QuimicaLibros.html?pagina=1

\section{Rocío Bruquetas Galán}

Instituto del Patrimonio Cultural de España. Secretaría de Estado de Cultura rocio.bruquetas@mcu.es

\section{Charo Fernández \\ ROA ESTUDIO S.C. \\ chafechafe33@hotmail.com}

Artículo enviado el 02/12/2013 